\title{
Bayesian Processor of Output for Probabilistic Quantitative Precipitation Forecast over Central and West Africa
}

\author{
Romeo S. Tanessong1,2*, Derbetini A. Vondou ${ }^{2}$, P. Moudi Igri², F. Mkankam Kamga² \\ ${ }^{1}$ School of Wood, Water and Natural Resources, Faculty of Agronomy and Agricultural Sciences, University of Dschang, \\ Dschang, Cameroon \\ ${ }^{2}$ Laboratory for Environmental Modelling and Atmospheric Physics, Department of Physics, University of Yaounde 1, \\ Yaounde, Cameroon \\ Email: *romeo.tanessong@univ-dschang.org
}

How to cite this paper: Tanessong, R.S., Vondou, D.A., Igri, P.M. and Kamga, F.M. (2017) Bayesian Processor of Output for Probabilistic Quantitative Precipitation Forecast over Central and West Africa. Atmospheric and Climate Sciences, 7, 263- 286.

http://dx.doi.org/10.4236/acs.2017.73019

Received: March 9, 2017

Accepted: July 1, 2017

Published: July 4, 2017

Copyright (c) 2017 by authors and Scientific Research Publishing Inc. This work is licensed under the Creative Commons Attribution-NonCommercial International License (CC BY-NC 4.0).

http://creativecommons.org/licenses/by-nc/4.0/

\begin{abstract}
The main goal of this work is a feasibility study for the Bayesian Processor of Output (BPO) method applied to tropical convective precipitation regimes over Central and West Africa. The study uses outputs from the Weather Research and Forecasting (WRF) model to develop and test the BPO technique. The model ran from June 01 to September 30 of 2010 and 2011. The BPO method is applied in each grid point and then in each climatic zone. Prior (climatic) distribution function is estimated from the Tropical Rainfall Measuring Mission (TRMM) data for the period 2002-2011. Many distribution functions have been tested for the fitting. Weibull distribution is found to be a suitable fitting function as shown by goodness of fit (gof) test in both cases. The rain pattern increases with the value of the probability p. BPO method noticeably improves the distribution of precipitation as shown by the spatial correlation coefficients. It better detects certain observed maxima compared to the raw WRF outputs. Posterior distribution (forecasting) functions allow for a simulated rainfall amount, to deduce the probability that observed rainfall falls above a given threshold. The probability of observing rainfall above a given threshold increases with simulated rainfall amounts.
\end{abstract}

\section{Keywords}

Probabilistic Quantitative Precipitation Forecast, BPO, WRF, Weibull Distribution

\section{Introduction}

Economies of sub-Saharan Africa largely depend on agriculture. The agriculture 
is essentially rain-fed. Precipitation is the most important and most widely studied weather variable ([1] [2] [3] [4] [5]). Important decisions in agriculture, hydrology, aviation, event planning and other areas depend on the presence or absence of precipitation, as well as precipitation accumulation. Reliable predictions of precipitation occurrence and precipitation amount are useful for above mentioned applications.

For these reasons, there is a great deal of research activities to improve quantitative precipitation forecast (QPF) and weather centers continuously evaluate their operational high-resolution limited-area models to trace error sources. QPF is particularly challenging over Equatorial Africa, especially capturing small convective cells that constitute most of the rain events ([6] [7] [8]).

Furthermore, QPFs obtained from a single numerical weather prediction (NWP) model are deterministic, and thus do not convey any information about the uncertainty about the prediction, which is a shortcoming in weather-related decision-making [9]. One approach to incorporating uncertainty information into weather forecasting is via ensembles of numerical forecasts ([10] [11]). While this is a major advance, the use of statistical post processing techniques for numerical forecasts remains essential. Several methods have been developed to statistically post process numerical predictions of precipitation occurrence and produce probabilistic quantitative precipitation forecasts. They include linear regression ([12] [13] [14]), quantile regression ([15] [16]), logistic regression ([17] [18]), neural networks ([19] [20]), binning techniques ([21] [22]), hierarchical models based on climatic prior distributions [23], and two-stage models in which a Gamma density is employed to model precipitation accumulation ([24] [25] [26] [27]).

In this paper, Bayesian Processor of Output for probabilistic quantitative precipitation forecasts is used. The Bayesian Processor of Output (BPO) is a theoretically-based technique for probabilistic forecasting of weather variates. It processes output from a numerical weather prediction (NWP) model and optimally fuses it with climatic data in order to quantify uncertainty about a predictand. The theoretical structures of the BPO are derived from the laws of probability theory.

As is well known, Bayes theorem provides the optimal theoretical framework for fusing information from different sources and for obtaining the probability distribution of a predictand, conditional on a realization of predictors, or conditional on an ensemble of realizations [28].

The objective of this work is a feasibility study for the Bayesian Processor of Output (BPO) method applied to tropical convective precipitation regimes over Central and West Africa. The paper is organized as follows: In Section 2, the model and experimental design are described, followed by the data used in this study. In Section 3, BPO techniques are briefly presented followed by the verification of BPO forecasts in Section 4. In Section 5, results for probabilistic forecasts of daily precipitation accumulation over the Central and West Africa is presented. Section 6 is devoted to the conclusion. 


\section{Model Description and Experimental Design}

\subsection{Model Description}

We performed simulations using version 3.3 of the Advanced Research Weather Research and Forecasting (ARW-WRF) model [29], which is being developed by the Mesoscale and Meteorology Division of the National Center for Atmospheric Research (NCAR). The WRF model is a numerical weather prediction model designed for a wide range of applications, ranging from idealized research to operational forecasting. It is a fully compressible, Euler nonhydrostatic model, with mass-based, terrain-following hydrostatic pressure vertical coordinates and Arakawa C-grid horizontal staggering. For the current work we choose the third-order Runge-Kutta split-explicit time-integration scheme and sixth-order centered differencing for advection and prognostic variables, conserving the flux form of mass, momentum, entropy, and scalars. Previous work has been done (not shown here) to determined satisfactory configurations by testing numerous physical parameterizations. Satisfactory Physical configurations are summarized in Table 1.

Hong et al. [30] developed the single-moment six-class microphysics scheme for the WRF, which includes graupel as an additional predictive variable. This microphysics scheme was found to significantly influence the evolution of surface precipitation [30]. Also used is the rapid radiative transfert model (RRTM) [31]. The RRTM longwave scheme accounts for multiple bands, trace gases, and microphysics species. The first-order closure scheme of Yonsei University (YSU) used for the planetary boundary layer $(\mathrm{PBL})$ is a non-local $\mathrm{K}$ scheme with an explicit entrainment layer and parabolic $\mathrm{K}$ profile in the unstable mixed layer. The Noah land surface model (Noah LSM) is used to calculate soil temperature and moisture. The Tiedtke convection scheme is a bulk flux convection scheme [32]. It handles three types of convection: deep, middle level, and shallow convection. In the Tiedtke scheme, only one convective cloud is considered, comprising one single saturated updraft. Entrainment and detrainment between the cloud and the environment can take place at any level between the free convection level and the zero-buoyancy level. There is also one single downdraft extending from the free sinking level to the cloud base. The mass flux at the top of the downdraft is a constant fraction of the convective mass flux at the cloud base. This downdraft is assumed to be saturated and is kept at saturation by evaporating precipitation. The original closure assumption for deep convection relies on a closure in

Table 1. Physics parameterizations used in the experiments.

\begin{tabular}{cc}
\hline Microphysics & WRF single-moment 6-class microphysics (WSM6) \\
Radiation & Rapid Radiative Transfer Model (RRTM) \\
longwave radiation scheme \\
Surface layer scheme \\
Surface physics \\
MBL scheme \\
Monin-Obukhov surface layer scheme \\
Numulus scheme
\end{tabular}


moisture convergence, while that used in this version is based on the convective available potential energy (CAPE) modified by [33].

\subsection{Experimental Setup}

The model is run from June 01 to September 30 of 2010 and 2011. The initial and boundary conditions are provided by the National Center for Environmental Prediction (NCEP) Global Forecasting System (GFS) three hourly products. We use the 0000 UTC cycle and run the WRF model for 48 hours starting at 0000 UTC. The model is set at a horizontal grid resolution of $25 \mathrm{~km} \times 25 \mathrm{~km}$ and has 41 vertical levels. Data analysed are total precipitation amount for the 24-hourperiod starting at 0600 UTC, thus having 6 hours of spinup (from 00 UTC to 0600 UTC).

\subsection{Area of Study}

The study area extends from $15^{\circ} \mathrm{W}$ to $30^{\circ} \mathrm{E}$ and $10^{\circ} \mathrm{S}$ to $30^{\circ} \mathrm{N}$ (Figure 1). A regionalization of the domain was carried out using the one-degree daily precipitation data set developed by the Global Precipitation Climatology Project (GPCP) [34] for the period 1997-2008.

Six distinct main climatic regions (Figure 2) were delineated using a Ward's clustering technique ([35] [36] [37] [38] [39]). In the following, the analysis will be conducted in each of the five regions (Region 2 to Region 6) that cover the study area (See Figure 2).

Region 2 covers arid (Sahara Desert) and semiarid (Sahel) zones over Mauritania, Mali, Niger, Chad and parts of Sudan, Cameroon and Nigeria. In the northern part of this region the climate is uniformly dry, with most areas receiving less than $130 \mathrm{~mm}$ /year of rain, some getting none at all for some years.

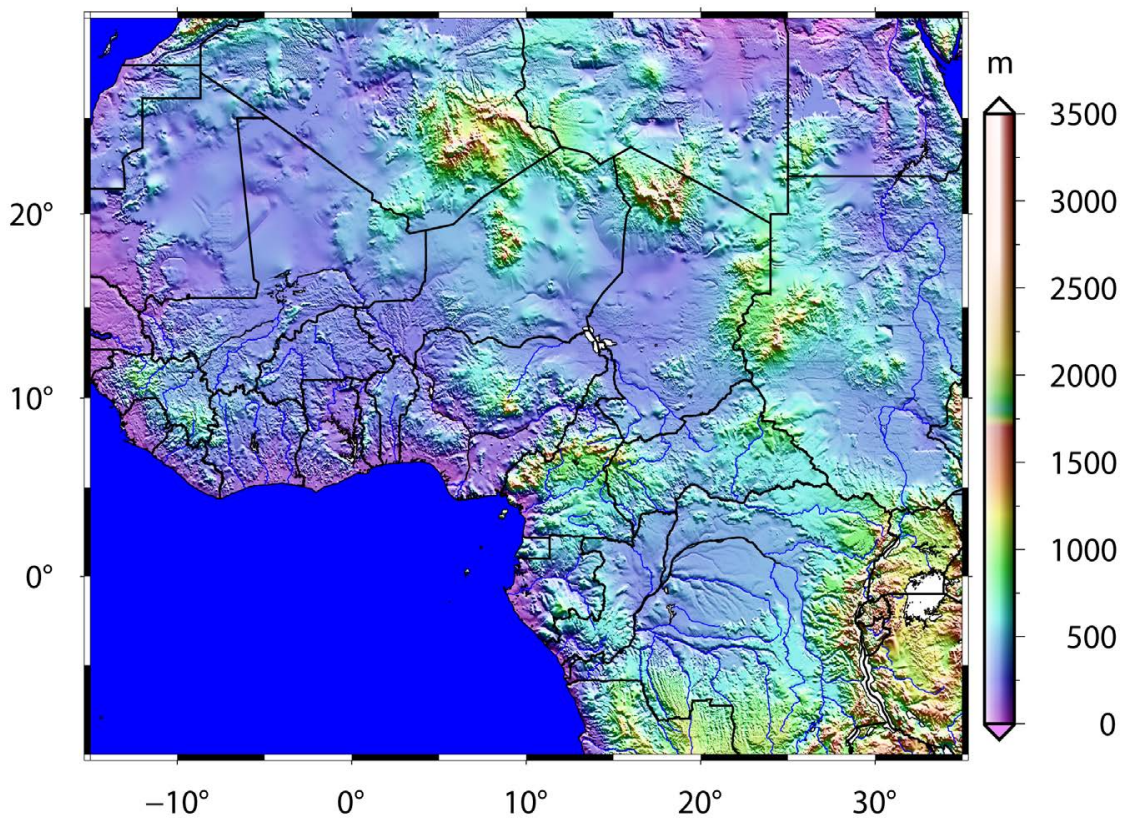

Figure 1. WRF model domain and topography. 


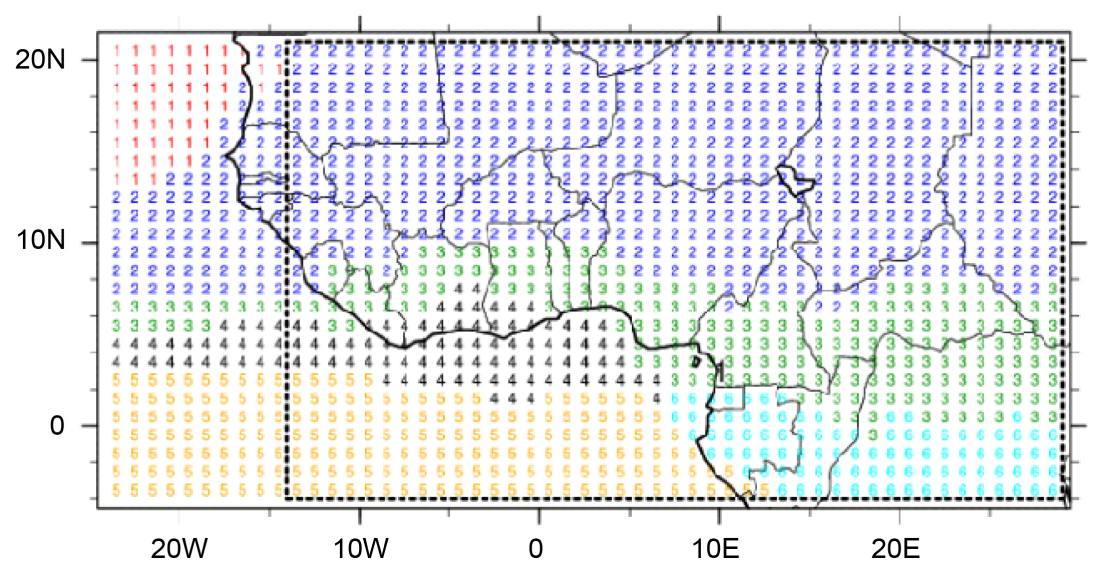

Figure 2. Homogeneous rainfall regions for the June-September (JJAS) season.

The southern part serves as a transition zone between the arid Sahara and the wetter savanna region further south. Annual rainfall averages between 100 and $200 \mathrm{~mm}$ received from June to September (Figure 3). Region 3 covers Liberia, Ivory Coast, Ghana, Togo, Benin, Nigeria, Cameroon and Central African Republic, in the area bordering the Gulf of Guinea. It has both areas of hot dry season (moderate rainfall) and wet climate (high, all-year rainfall). Rainfall ranges between 100 and $400 \mathrm{~mm} /$ year in the former and as much as $1800 \mathrm{~mm}$ in the latter. Region 4 represents the transition between the ocean and the continent. Breeze phenomena are very recurrent. Region 5 covers the South Atlantic Ocean and represents an oceanic climate. Region 6 is characterized by the tropical wet climate.

\subsection{Data Sources and Structure}

\subsubsection{TRMM 3B42}

For the purpose of verification we used Tropical Rainfall Measuring Mission (TRMM) data as ground truth. TRMM data show that the JJAS seasons 2010 and 2011 were wet and dry respectively (Figure 4). TRMM was used instead of gauge data because of the irregular spatial distribution of gauges and the sparse network in the region. TRMM is a joint mission of the American National Aeronautics and Space Administration (NASA) and the Japanese National Space Development Agency (NASDA) to measure precipitation in the tropics and subtropics. In this work, version 6 of the 3B42 data set is used. It provides three hourly estimations of rainfall on a $0.25^{\circ} \times 0.25^{\circ}$ grid. These data are provided online by the NASA at http://mirador.gsfc.nasa.gov. Nicholson et al. [40] evaluated TRMM products over West Africa over the May to September season. They found that TRMM-merged rainfall products showed excellent agreement with gauge data.

Although the $0.25^{\circ}$ grid spacing of TRMM data is close to WRF's $25 \mathrm{~km}$, they were regridded in order to achieve coincidence of both grids points.

\subsubsection{DD GPCP Precipitation Data}

The 1DD GPCP data set is a $1^{\circ} \times 1^{\circ}$ longitude/latitude precipitation product 


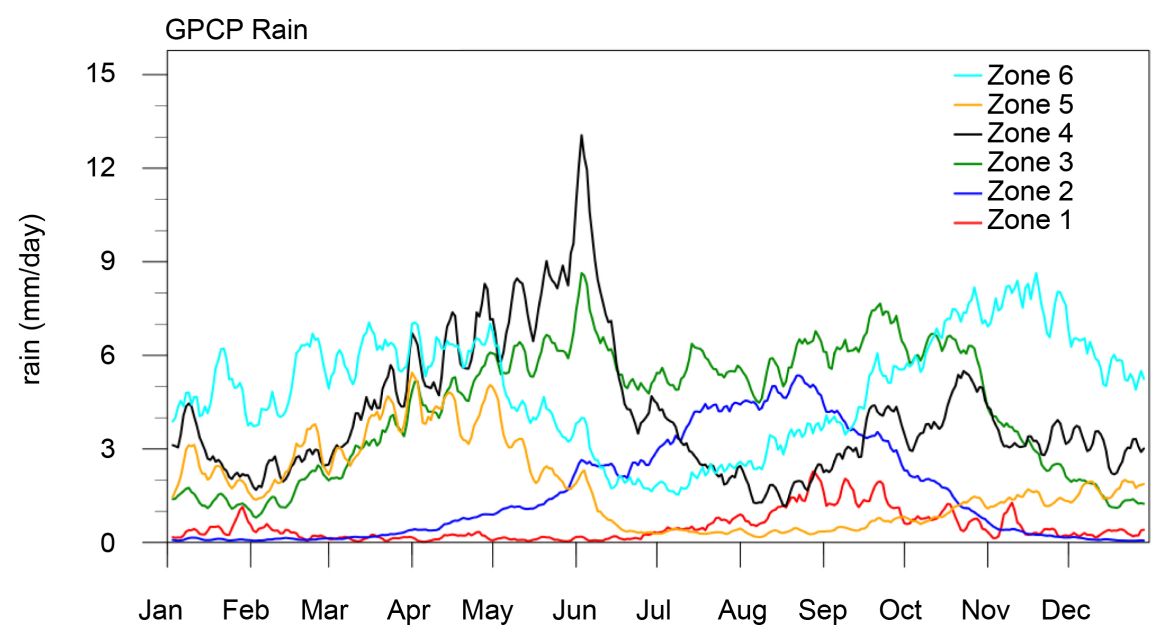

Figure 3. Mean rainfall (mm) for the period 1997 to 2008.

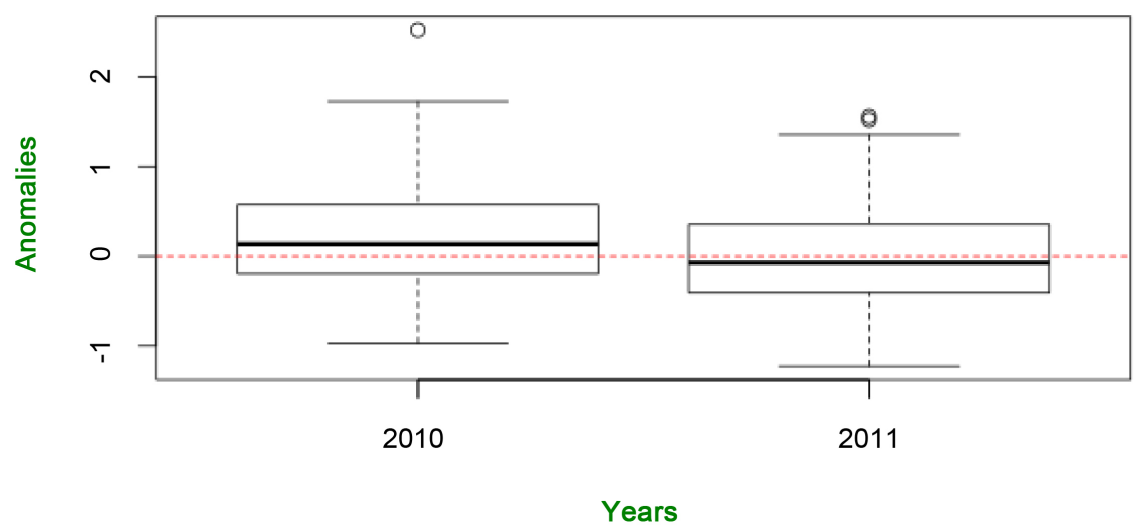

Figure 4. Mean JJAS anomalies for years 2010 and 2011.

from Global precipitation Climatology Project. The GPCP algorithm combines precipitation estimates from several sources, including infrared (IR) and passive microwave (PM) rain estimates, and rain gauge observations [41]. The IR data come mainly from the different Geostationary Meteorological Satellites but also from polar-orbiting satellites for high latitudes [42]. The microwave data come from the Special Sensor Microwave Imager (SSM/I) onboard the Defense Meteorological Satellite Program. The multi-satellite estimates are first adjusted towards the large-scale gauge average for each grid box, and then combined with gauge analysis using a weighted average. 1DD GPCP Precipitation data are used in the present work to subdivide the study area into subdomains and to determine seasonal cycle in each.

\section{Bayesian Processor of Output Techniques}

Following the ideas of Bayes, if we have a set of forecasts and past observations, we can use this prior information to improve future forecasts. Based on past couples of forecasts and observations, we can construct a model to link each forecast amount to the probability of observed amount. Example, determine the 
probability of observing a rainfall amount greater than $10 \mathrm{~mm}$, knowing that the forecast amount is $1 \mathrm{~mm}$. The concept is illustrated in Figure 5. The BPO is operationalized by the meta-Gaussian model ([43] [44] [45]). It is described below in terms of input elements and forecasting equations.

\subsection{Input Elements}

The following algorithm defines the input elements, outlines the estimation procedure, and details the calculation of the posterior parameters (the parameters of the forecasting equations).

Step 0: Given are two samples, the climatic sample of the predict and $W$, and the joint sample of the predictor vector and the predict and $(X, W)$, respectively:

$$
\begin{gathered}
\{w(n): n=1, \cdots, M\}, \\
\{(x(n), w(n)): n=1, \cdots, N\},
\end{gathered}
$$

where $x(n)=\left(x_{1}(n), \cdots, x_{I}(n)\right)$ and $N \leq M$; all realizations of $W$ from the joint sample are included in the climatic sample. The index $I$ scans over the number of predictors.

Step 1: Using the climatic sample, the prior (climatic) distribution function $G$ of predict and $W$ is estimated, such that $G(w)=P(W \leq w) ; P$ denotes the probability.

Let $\mathrm{g}$ denote the corresponding prior (climatic) density function of $W$.

Step 2: Using the marginal sample $\left\{x_{i}(n): n=1, \cdots, N\right\}$ of the joint sample, we estimate the marginal distribution function $\bar{K}_{i}$ of predictor $X_{i}$, such that

$$
\bar{K}_{i}\left(x_{i}\right)=P\left(X_{i} \leq x_{i}\right), i=1, \cdots, I .
$$

(The bar over $K_{i}$ signifies that this is only an initial distribution function of $X_{i}$, which need not cohere to the specified prior distribution function of $W$ and the yet-to-be-constructed family of likelihood functions. This detail is accounted for in the derivation of the meta-Gaussian BPO, and thus need not be considered in application.)

Step 3: The normal quantile transform (NQT) of the predictand and of every predictor is defined:

$$
\begin{gathered}
V=Q^{-1}(G(W)), \\
Z_{i}=Q^{-1}\left(\bar{K}_{i}\left(X_{i}\right)\right), i=1, \cdots, I,
\end{gathered}
$$

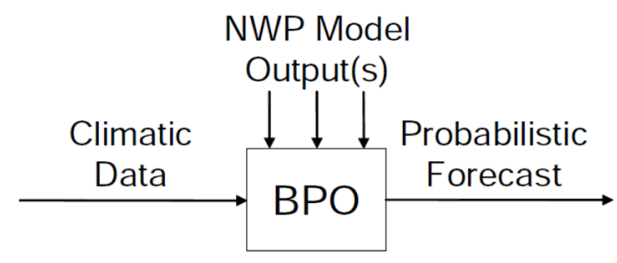

Figure 5. Concept of BPO technique. 
where $Q$ is the standard normal distribution function, and $Q^{-1}$ is the inverse of $Q$. Next, we apply the NQT to each realization in the original joint sample; specifically, for $n=1, \cdots, N$, we calculate $v(n)=Q^{-1}(G(w(n)))$, $z_{i}(n)=Q^{-1}\left(\bar{K}_{i}\left(x_{i}(n)\right)\right), i=1, \cdots, I$; then the transformed joint sample is evaluated $\{(z(n), v(n)): n=1, \cdots, N\}$, where $z(n)=\left(z_{1}(n), \cdots, z_{I}(n)\right)$.

Step 4: Using the transformed joint sample, we estimate the following moments. For the transformed predictand $V, \mu_{0}=E(V), \sigma_{0}^{2}=\operatorname{Var}(V)$.

For every transformed predictor $Z_{i}, i=1, \cdots, I, \mu_{i}=E\left(Z_{i}\right), \sigma_{i}^{2}=\operatorname{Var}\left(Z_{i}\right)$, $\sigma_{i 0}=\operatorname{Cov}\left(Z_{i}, V\right)$. For $i=1, \cdots, I-1$ and $j=i+1, \cdots, I, \sigma_{i j}=\operatorname{Cov}\left(Z_{i}, Z_{j}\right)$.

The estimates of variances and covariances should be the maximum likelihood estimates (i.e., they should be calculated using $\mathrm{N}$ as the divisor).

Step 5: We form two I-dimensional column vectors $\mu=\left(\mu_{1}, \cdots, \mu_{I}\right)$, $\sigma=\left(\sigma_{10}, \cdots, \sigma_{I 0}\right)$, the transpose of vector $\sigma$, which is denoted $\sigma^{\mathrm{T}}$, and an $I \times I$ symmetric matrix $\Sigma=\left\{\sigma_{i j}\right\}$, with $\sigma_{i i}=\sigma_{i}^{2}$ for $i=1, \cdots, I$, and $\sigma_{j i}=\sigma_{i j}$ for $i=1, \cdots, I-1$ and $j=i+1, \cdots, I$. Next we calculate an $I \times I$ symmetric matrix

$$
M=\left(\Sigma-\sigma_{0}^{-2} \sigma \sigma^{\mathrm{T}}\right)^{-1}
$$

Step 6: The values of the posterior parameters are calculated as follows:

$$
\begin{gathered}
T=\left(\frac{\sigma_{0}^{4}}{\sigma^{\mathrm{T}} M \sigma+\sigma_{0}^{4}}\right)^{\frac{1}{2}} \\
c^{\mathrm{T}}=\frac{T^{2}}{\sigma_{0}^{2}} \sigma^{\mathrm{T}} M \\
c_{0}=c^{\mathrm{T}}\left(\frac{\mu_{0}}{\sigma_{0}^{2}} \sigma-\mu\right)
\end{gathered}
$$

where $c^{\mathrm{T}}=\left[c_{1}, \cdots, c_{I}\right]$ is an I-dimensional row vector.

\subsection{Forecasting Equations}

Given a prior distribution function $\mathrm{G}$ of predict and $\mathrm{W}$ and given a realization $x=\left(x_{1}, \cdots, x_{I}\right)$ of the predictor vector, the meta-Gaussian posterior distribution function of predict and $W$ is specified by the equation

$$
\Phi(w)=Q\left(\frac{1}{T}\left[Q^{-1}(G(w))-\sum_{i=1}^{I} c_{i} Q^{-1}\left(\bar{K}_{i}\left(x_{i}\right)\right)-c_{0}\right]\right)
$$

For any number $p$ such that $0<p<1$, the p-probability posterior quantile of predict and $W$ is specified by the equation

$$
w_{p}=G^{-1}\left(Q\left(\sum_{i=1}^{I} c_{i} Q^{-1}\left(\bar{K}_{i}\left(x_{i}\right)\right)+c_{0}+T Q^{-1}(p)\right)\right)
$$

Given also a prior density function $\mathrm{g}$ of predict and $W$, the meta-Gaussian posterior density function of predict and $W$ is specified by the equation

$$
\phi(w)=\frac{1}{T} \exp \left(\frac{1}{2}\left\{\left[Q^{-1}(G(w))\right]^{2}-\left[Q^{-1}(\Phi(w))\right]^{2}\right\}\right) g(w)
$$


In the current work, one predictor is used. When there is only one predictor $(I=1)$, its subscript is omitted. Thus $X$ replaces $X_{1}, \bar{K}$ replaces $\bar{K}_{1}$, and the forecasting Equations (5)-(6) can be written

$$
\begin{gathered}
\Phi(w)=Q\left(\frac{1}{T}\left[Q^{-1}(G(w))-\sum_{i=1}^{I} c_{i} Q^{-1}(\bar{K}(x))-c_{0}\right]\right) \\
w_{p}=G^{-1}\left(Q\left(\sum_{i=1}^{I} c_{i} Q^{-1}(\bar{K}(x))+c_{0}+T Q^{-1}(p)\right)\right)
\end{gathered}
$$

In the following, processing will be done by grid point and climatic zones.

\section{Results}

\subsection{Processing by Grid Point}

\subsubsection{Prior Distribution Function}

The prior distribution function $\mathrm{G}$ of precipitation amount $W$ is conditional on precipitation occurrence: $G(w)=P(W \leq w \mid W>0)$. It is estimated from the TRMM data for the period 2002-2011. This estimation is done at any grid point. Many distribution functions are tested for the fitting. Weibull distribution is found to be a suitable fitting function as shown by goodness of fit (gof) test (not shown here).

\subsubsection{Marginal Distribution Function}

The single predictor $X$ is the estimate of the 24-h total precipitation. The marginal distribution function $\bar{K}$ of $X$ is conditional on precipitation occurrence:

$\bar{K}(x)=P(X \leq x \mid W>0)$. It is estimated for WRF model outputs cover the period JJAS2010-2011 from the joint sample. Weibull distribution is also found to be more suitable.

\subsubsection{Transformed Rain $w_{p}$}

Once the five elements $\left(G, \bar{K}, T, c_{0}, c_{1}\right)$ are specified, the transformed rain may be calculated, given any value $\mathrm{p}$ of the probability.

From the definition, the number $\mathrm{p}$ is the probability that the value of the precipitation is less than or equal to $\mathrm{w} p$. In this section, the number $\mathrm{p}$ is simply interpreted as the probability that the rain is equal to $\mathrm{w} p$. Only values of $\mathrm{p}$ for which the spatial distribution of precipitation is close to the observations will be presented.

Figure 6(a) represents the weather of June 10, 2010. This figure shows that the rain pattern produced by the BPO method is denser than those produced by WRF and TRMM for great values of the probability $\mathrm{p}$. The algorithm used in the BPO method gives the cumulative distribution (CDF) of the rains. This is why the intensity of rainfall increases with the probability. Indeed, the chances of observing the precipitation less than $5 \mathrm{~mm}$ at a point are less than the chances to observe precipitation less than $10 \mathrm{~mm}$ at this point. In the following, $\mathrm{p}$ will be simply taken as the probability that the rain patterns be that shown on the maps.

BPO method introduces a noise, that is, it introduced rains in some parts of 


\section{a) $\quad$ Rain (mm/day): 2010-06-10}
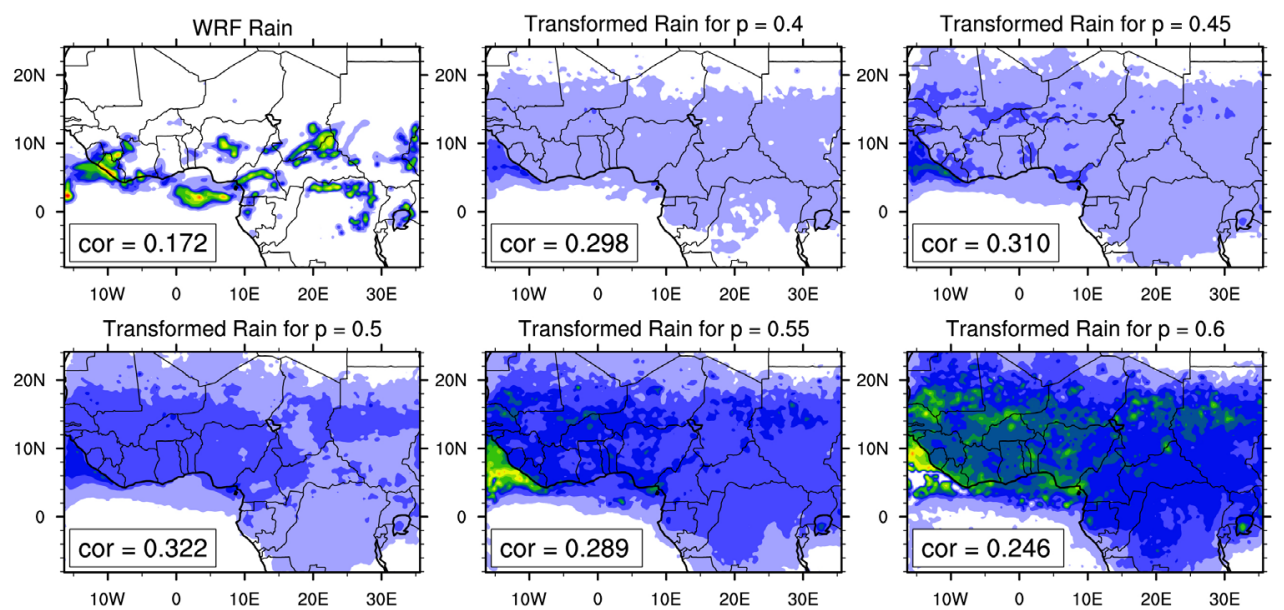

Transformed Rain for $\mathrm{p}=0.6$
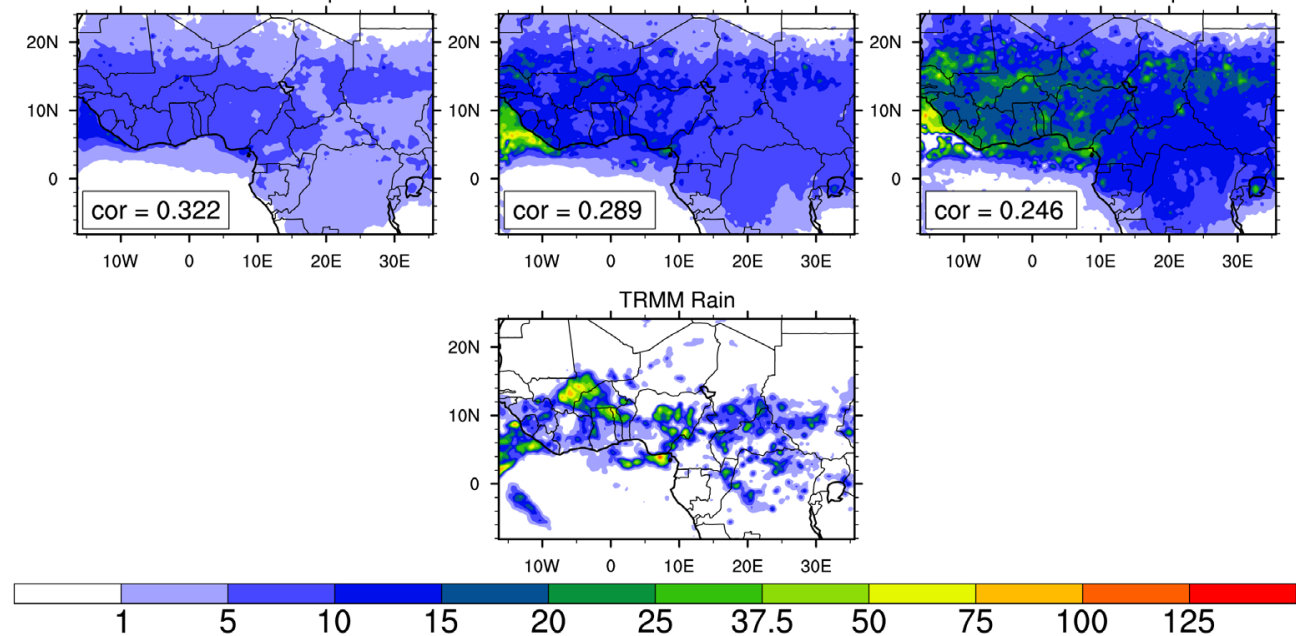

10W $0 \quad 10 \mathrm{E} \quad 20 \mathrm{E} \quad 30 \mathrm{E}$

b)

Rain (mm/day): 2010-06-10
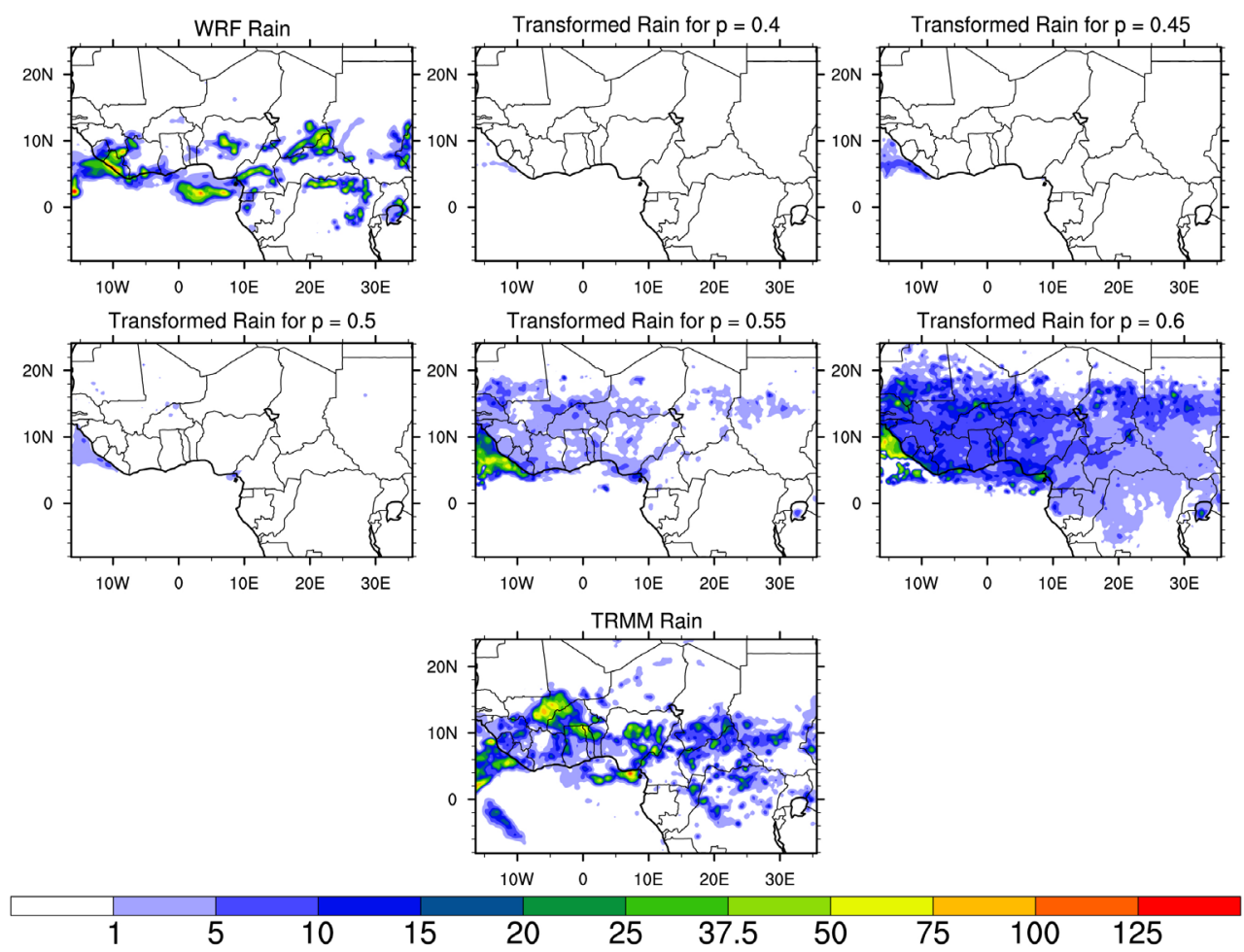

Figure 6. (a) 24-h accumulated spatial distribution rainfall amount: 10-06-2010. (b) Same as (a) but the climatological mean has been removed. 
the field, compared to observations.

For $\mathrm{p}=0.4$ (Figure 6(a)), the maximum rainfall is located on the coast of Liberia, Sierra Leone and Guinea. The intensity of rainfall in the region is about 15 $\mathrm{mm}$. The TRMM observations confirm that these areas were rainy at June 10, 2010.

The observed intensity is $25 \mathrm{~mm}$ instead of $15 \mathrm{~mm}$ as forecasted by the BPO method for $\mathrm{p}=0.4$. For $\mathrm{p}=0.45$, other maxima are found over West Cameroon and northern Burkina Faso. It is generally found that when the probability $\mathrm{p}$ increases, the areas that have the maxima are preserved with the difference that intensity also increases. For $\mathrm{p}=0.6$, some observed maxima are located by the BPO method. These include the maximum observed on the north of the Central African Republic and the south-eastern Nigeria.

Figure 7(a) displays rainfall patterns of June 15, 2010. The field and intensity of rainfall increase with the value of the probability $p$. Maxima are detected by the BPO method especially for $\mathrm{p}=0.45,0.5,0.55$ and 0.6 . The maximum observed in southern Nigeria is well reproduced by the BPO method. Intensities are in the same order for $\mathrm{p}=0.6$. This intensity is about $50 \mathrm{~mm}$. For the values of $\mathrm{p}$ less than 0.6 , these areas of maximum intensity are well detected but the intensities are underestimated. The maxima observed on the coast of Liberia, Sierra Leone, the Guinea Conakry are detected by the BPO method. The TRMM observations also show maxima rainfall in southern Central African Republic, northern Democratic Republic of Congo. These maxima were not well localized by BPO method.

Figure 8(a) shows the rains patterns of 20-07-2010. The maximum observed on the coast of Guinea Conakry is well locate for $\mathrm{p}=0.6$. Some maxima observed in southern Mali, south of Niger and central Nigeria have not been well detected by the BPO method.

Given the foregoing, it is found that BPO method introduced background noise. It provides low rainfall almost throughout the study area especially when the value of the probability $\mathrm{p}$ increases. This led us to subtract the average daily climatology $(8.8 \mathrm{~mm})$ over the entire region to get rid of this noise. Figure 6(b), Figure 7(b) and Figure 8(b) show these new maps. Figure 6(b) shows the rains patterns of 10-06-2010. This field is less dense than that of Figure 6(a). Some maxima are well captured by the BPO method. These maxima are observed on the coast of Sierra Leone, eastern Chad, the southwest coast of Cameroon and eastern Senegal. In general, withdrawal of the daily average climatology reduces the field of the rains. For some values of the probability $(\mathrm{p}=0.55$ and $\mathrm{p}=0.6$ ), this field is close enough observed field.

\subsection{Processing by Climatic Zones}

In the following, the analysis will be conducted in each of the five regions (Region 2 to Region 6) that cover the study area (see Figure 2). The following figures show prior and posterior distribution functions and prior and posterior densities.

\subsubsection{Region 2}

Figure 9(a) represents the prior (climatic) distribution function $G$ and three 
a)

Rain (mm/day): 2010-06-15
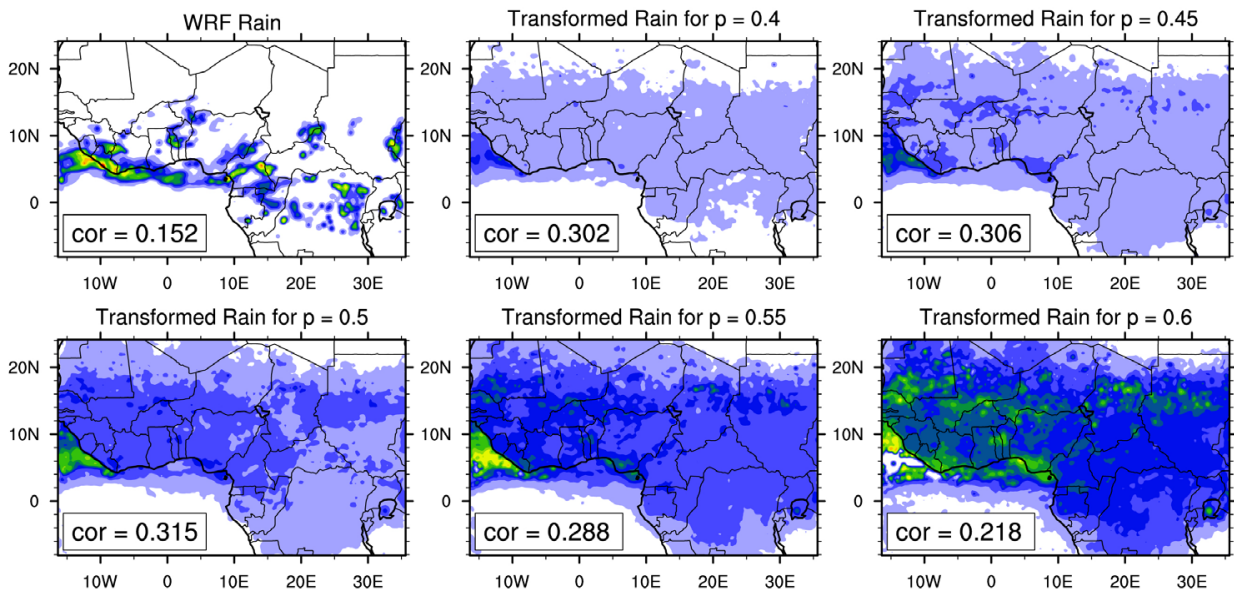

Transformed Rain for $p=0.55$

Transformed Rain for $\mathrm{p}=0.6$
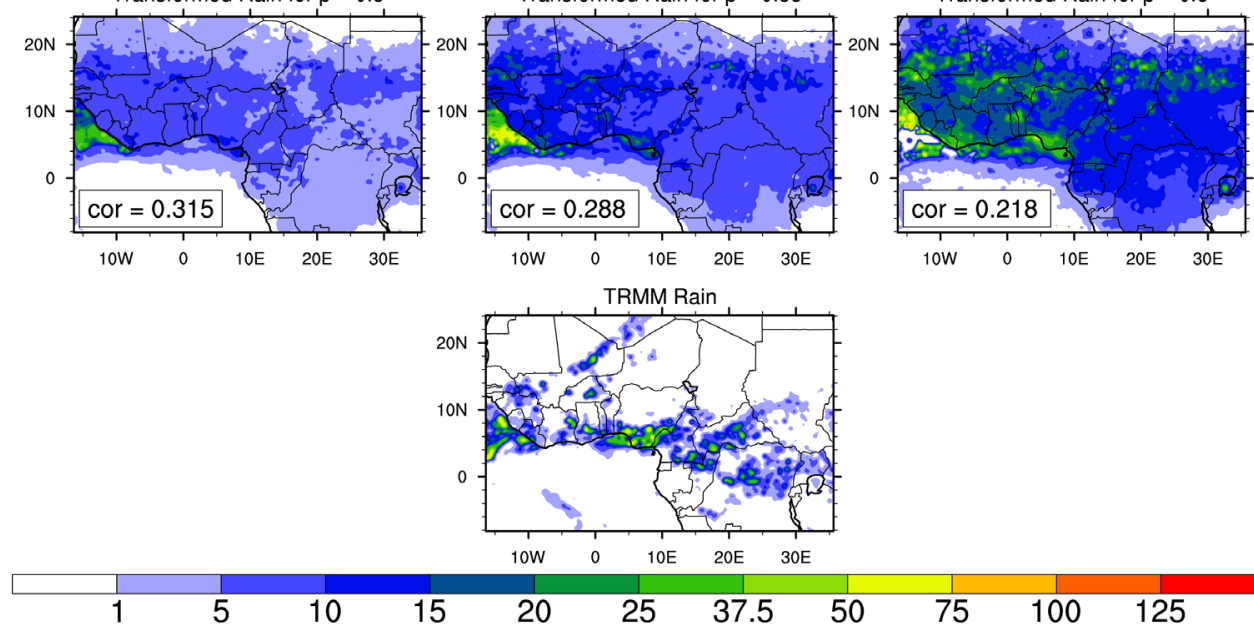

b)

\section{Rain (mm/day): 2010-06-15}
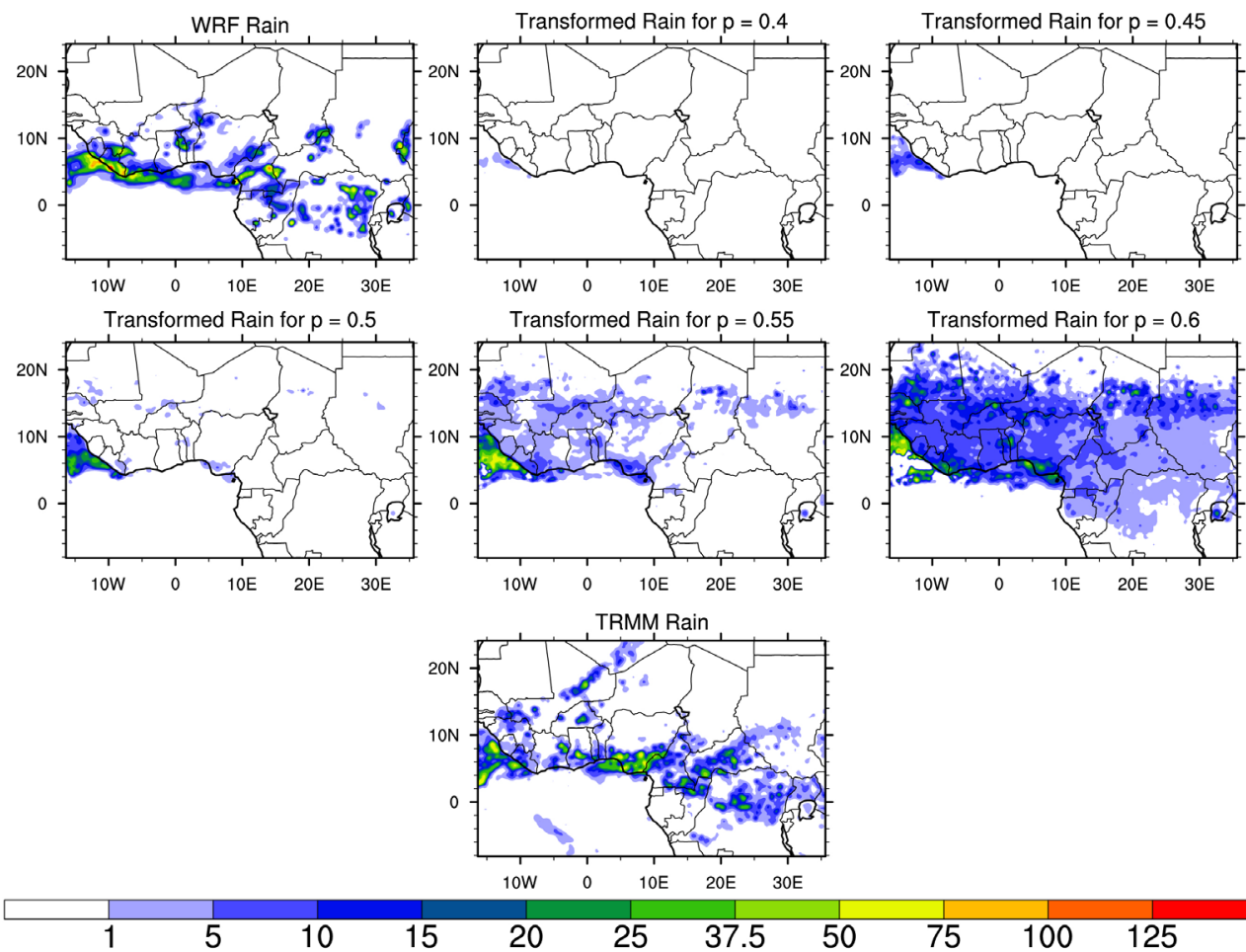

Figure 7. (a) 24-h accumulated spatial distribution rainfall amount: 15-06-2010. (b) Same as (a) but the climatological mean has been removed. 
a)
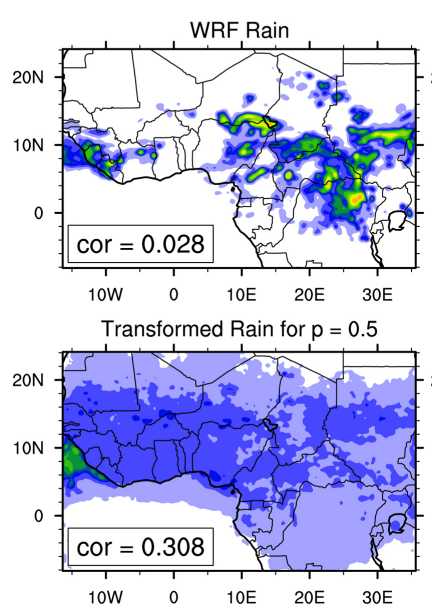

\section{Rain (mm/day): 2010-07-20}
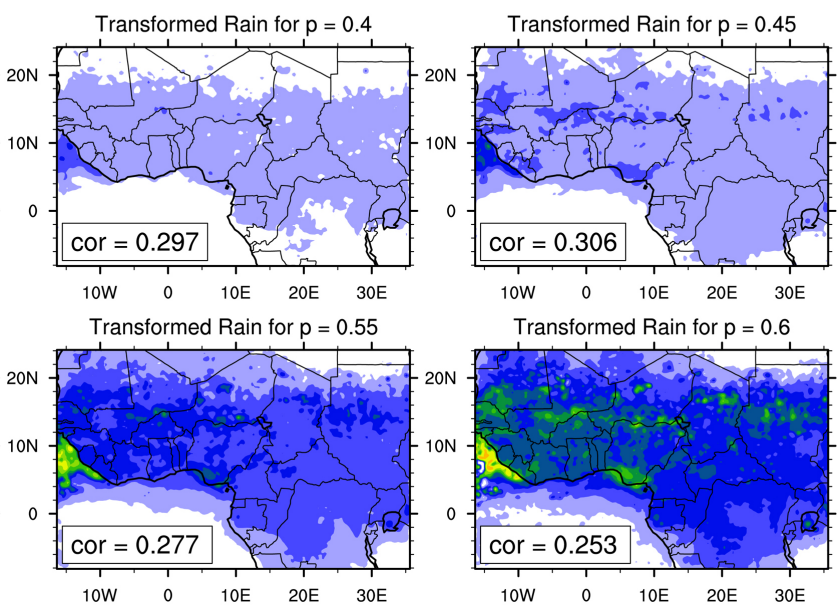
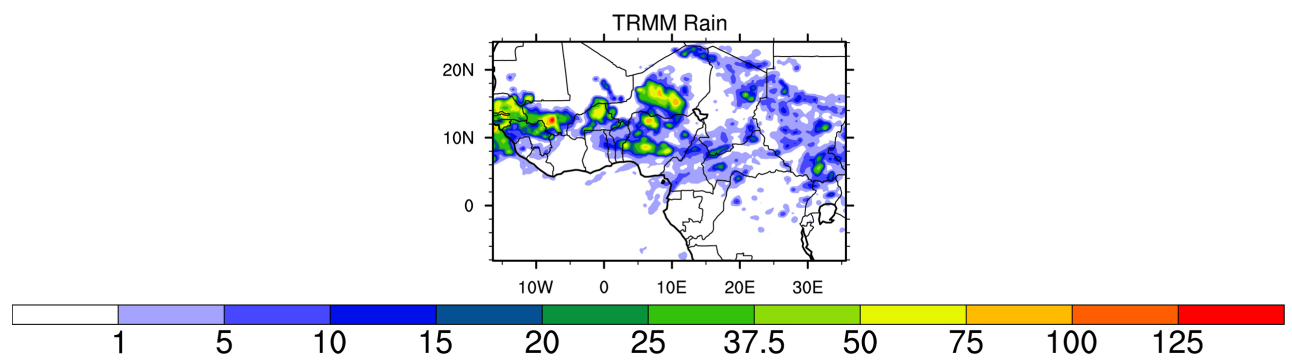

b)

Rain (mm/day): 2010-07-20
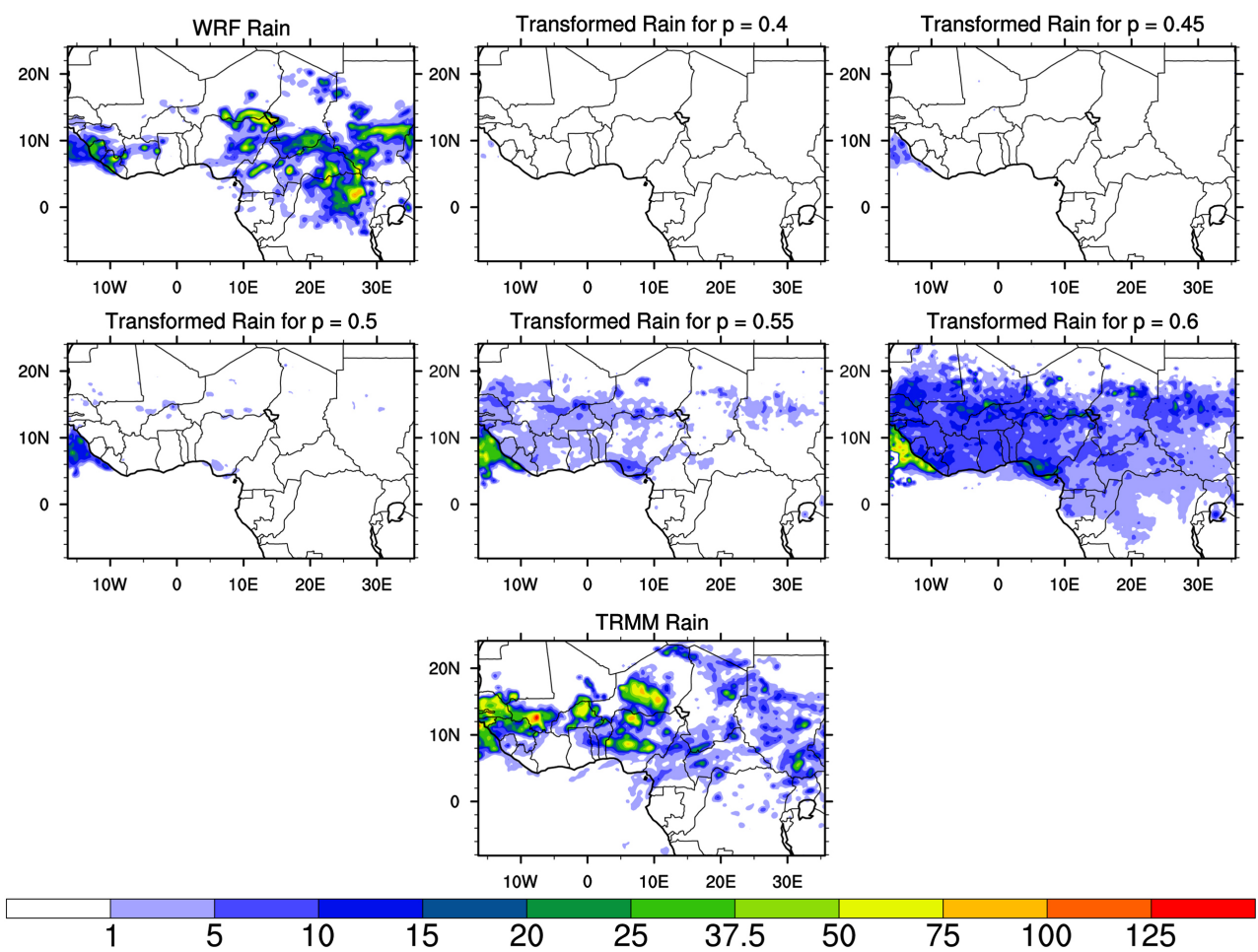

Figure 8. (a) 24-h accumulated spatial distribution rainfall amount: 20-07-2010. (b) Same as (a) but the climatological mean has been removed. 
Region 2
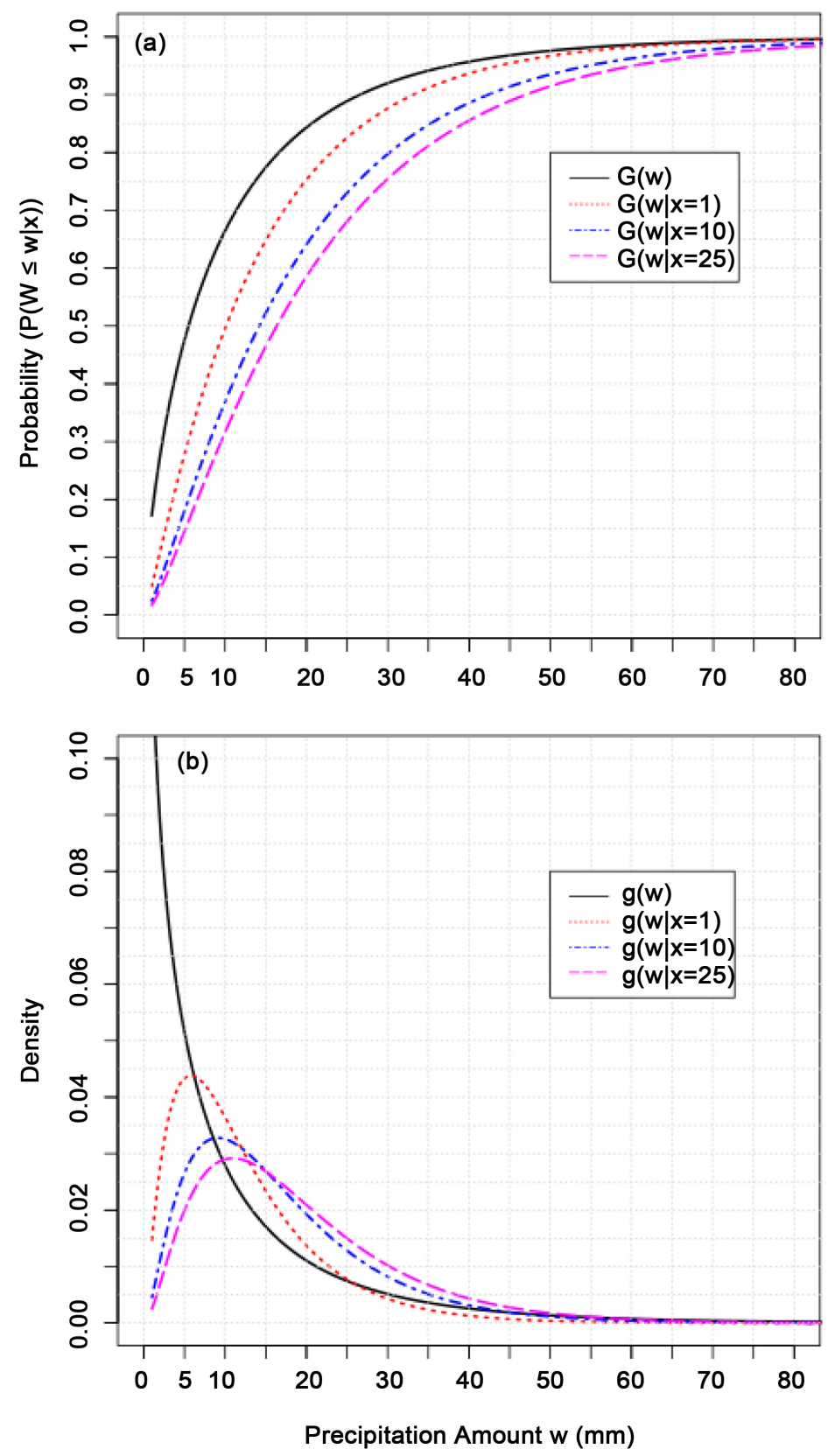

Figure 9. Examples of probabilistic forecasts of the precipitation amount $\mathrm{W}$, conditional on precipitation occurrence, $\mathrm{W}$ greater than 0 , and based on three different realizations $\mathrm{x}=1,10,25[\mathrm{~mm}]$ of predictor $\mathrm{X}$ for $24-\mathrm{h}$ total precipitation amount output from the WRF model: (a) the prior (climatic) distribution function $\mathrm{G}$ and three posterior distribution functions $G(w \mid x=1), G(w \mid x=10), G(w \mid x=25)$; (b) the prior (climatic) density function $g$ and three posterior density functions $g(w \mid x=1), g(w \mid x=$ $10), g(w \mid x=25)$.

posterior distributions functions based on three different realizations: $1 \mathrm{~mm}, 10$ $\mathrm{mm}$ and $25 \mathrm{~mm}$ of predictor $X$. For simulated value of $1 \mathrm{~mm}$ of precipitation, the probability of observing an amount less than or equal to $20 \mathrm{~mm}$ of rainfall at 
any point in the Region 2 is 0.75 . This means that there is $75 \%$ chance to observe at any point of this region an amount of rain less or equal to $20 \mathrm{~mm}$. We deduce that the probability of observing rainfall amount greater than $20 \mathrm{~mm}$ is 0.25 , that is there is only $25 \%$ chance to observe rain greater than $20 \mathrm{~mm}$ in intensities.

For simulated value of $10 \mathrm{~mm}$ of rainfall, the probability of observing rainfall less than or equal to $20 \mathrm{~mm}$ is 0.65 . That is $65 \%$ chance to observe rainfall $\leq 20$ $\mathrm{mm}$ when the model simulates $10 \mathrm{~mm}$ of precipitation at a point. We deduce from the above that the probability of observing rainfall greater than $20 \mathrm{~mm}$ is 0.35 .

Thus, there is $35 \%$ chance of observing rainfall intensities greater than $20 \mathrm{~mm}$ at a point when the model simulates $10 \mathrm{~mm}$ of rainfall. For a simulated value of $25 \mathrm{~mm}$, the probability of observing rainfall $\leq 20 \mathrm{~mm}$ is 0.58 , that is there is $58 \%$ of chance of observing rainfall $\leq$ to $20 \mathrm{~mm}$ when the WRF model simulates 25 $\mathrm{mm}$ of rainfall at a point. The probability to observe rainfall intensity greater than $20 \mathrm{~mm}$ is 0.42 ; that is $42 \%$ of chance.

Based on the above analysis, it appears that the probability of observing rainfall above a given threshold increases with simulated rainfall amounts. This result is consistent with that of Tanessong et al. [46].

Figure 9 (b) represents the prior (climatic) density function $g$ and three posterior density functions based on three different realizations of predictor $X: 1$ $\mathrm{mm}, 10 \mathrm{~mm}$ and $25 \mathrm{~mm}$. For a simulated rainfall amount of $1 \mathrm{~mm}$, the most likely rainfall value that can be observed is $5 \mathrm{~mm}$. This most likely value is $8 \mathrm{~mm}$ when simulated rainfall amount is $10 \mathrm{~mm}$ and becomes $12 \mathrm{~mm}$ for a simulated rainfall amount of $25 \mathrm{~mm}$. Thus, when the simulated rainfall amount increases, the chances of observing heavy rainfall also increase. These results thus strengthen those found previously. Figure 9(b) also shows that the density decreases as the observed quantities increase, indicating that heavy rainfall events are rare and therefore difficult to predict.

\subsubsection{Region 3}

Figure 10(a) represents the prior (climatic) distribution function $G$ and three posterior distributions functions based on three different realizations: $1 \mathrm{~mm}, 10$ $\mathrm{mm}$ and $25 \mathrm{~mm}$ of predictor $X$. For simulated rainfall amount of $1 \mathrm{~mm}$, the probability to observe rainfall $\leq 20 \mathrm{~mm}$ is 0.90 , that is $90 \%$ of chances. Then the chances of observing the rainfall amounts greater than $20 \mathrm{~mm}$ are $10 \%$ only when simulated rainfall amount is $1 \mathrm{~mm}$. For simulated rainfall amounts of 10 $\mathrm{mm}$, the probability of observing rainfall $\leq 20$ is $0.75 \mathrm{~mm}$, for example; that is $75 \%$ chance.

Thus the probability of observing rainfall greater than $20 \mathrm{~mm}$ is 0.25 ; yielding $25 \%$ chance. For simulated rainfall amount of $25 \mathrm{~mm}$, the probability of observing rainfall $\leq 20 \mathrm{~mm}$ is $0.7 ; 70 \%$ chance. The chances of observing the rainfall greater than $20 \mathrm{~mm}$ are $30 \%$.

Unlike Region 2, we note that the chances of observing rainfall greater than a given threshold increase weakly when the simulated rainfall amount increase in 
Region 3
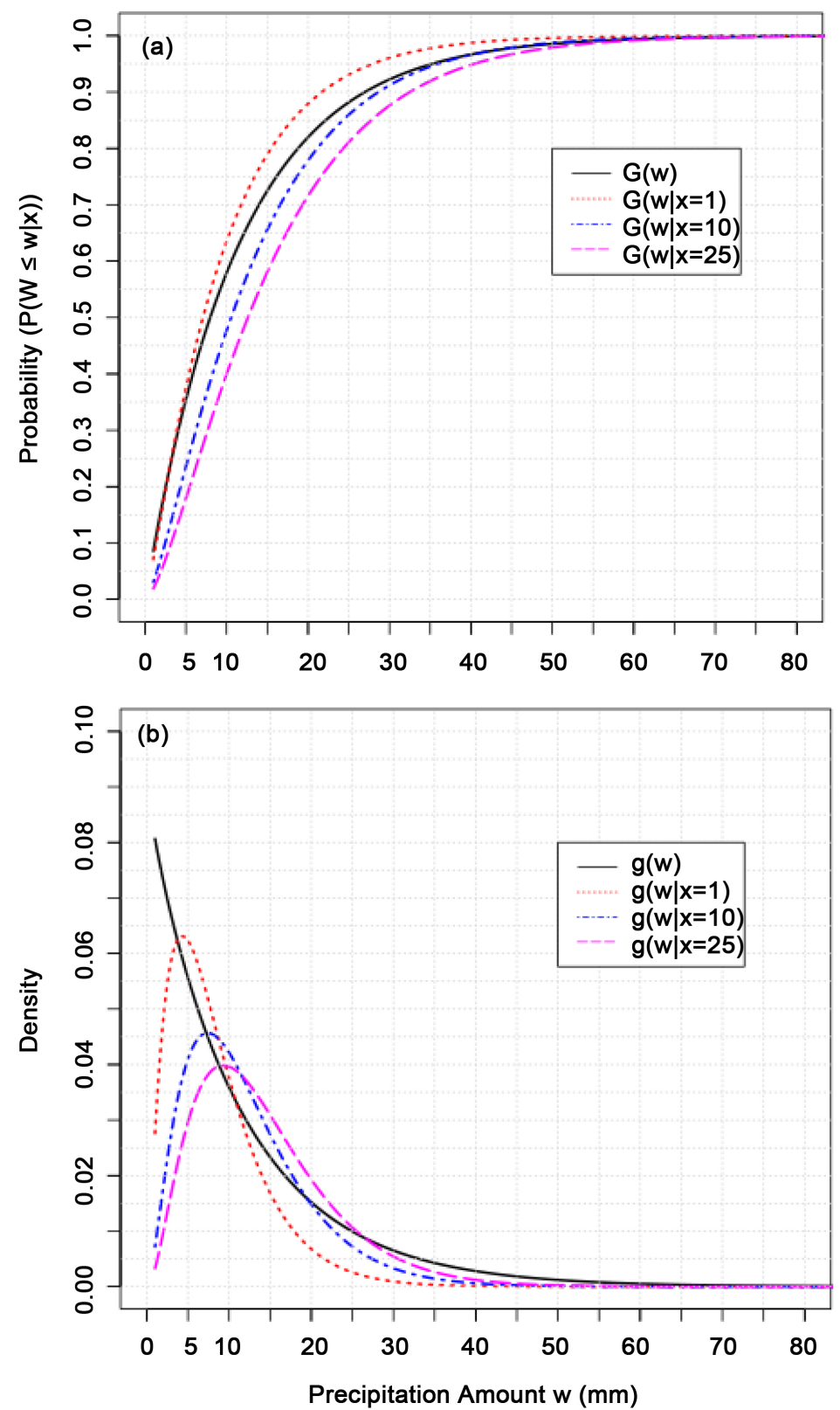

Figure 10. Examples of probabilistic forecasts of the precipitation amount $\mathrm{W}$, conditional on precipitation occurrence, $\mathrm{W}$ greater than 0 , and based on three different realizations $\mathrm{x}=1,10,25[\mathrm{~mm}]$ of predictor $\mathrm{X}$ for 24-h total precipitation amount output from the WRF model: (a) the prior (climatic) distribution function $G$ and three posterior distribution functions $\mathrm{G}(\mathrm{w} \mid \mathrm{x}=1), \mathrm{G}(\mathrm{w} \mid \mathrm{x}=10), \mathrm{G}(\mathrm{w} \mid \mathrm{x}=25)$; (b) the prior (climatic) density function $\mathrm{g}$ and three posterior density functions $\mathrm{g}(\mathrm{w} \mid \mathrm{x}=$ $1), g(w \mid x=10), g(w \mid x=25)$.

Region 3. This could be due to complex topography of Region 3. This region includes the Niger valley, the west highlands of Cameroon, the Adamawa Plateau of Cameroon and Mount Cameroon. The climate of this region is very diverse and complex. 
Figure 10(b) represents the prior (climatic) density function $g$ and three posterior density functions. For the simulated rainfall amount of $1 \mathrm{~mm}$, the most likely value that can be observed is $4 \mathrm{~mm}$ with a density of 0.06 . The most likely value is $7 \mathrm{~mm}$ for simulated rainfall amount of $10 \mathrm{~mm}$. It is $10 \mathrm{~mm}$ when the simulated rainfall amount is $25 \mathrm{~mm}$.

\subsubsection{Region 4}

Figure 11(a) represents the prior (climatic) distribution function $G$ and three
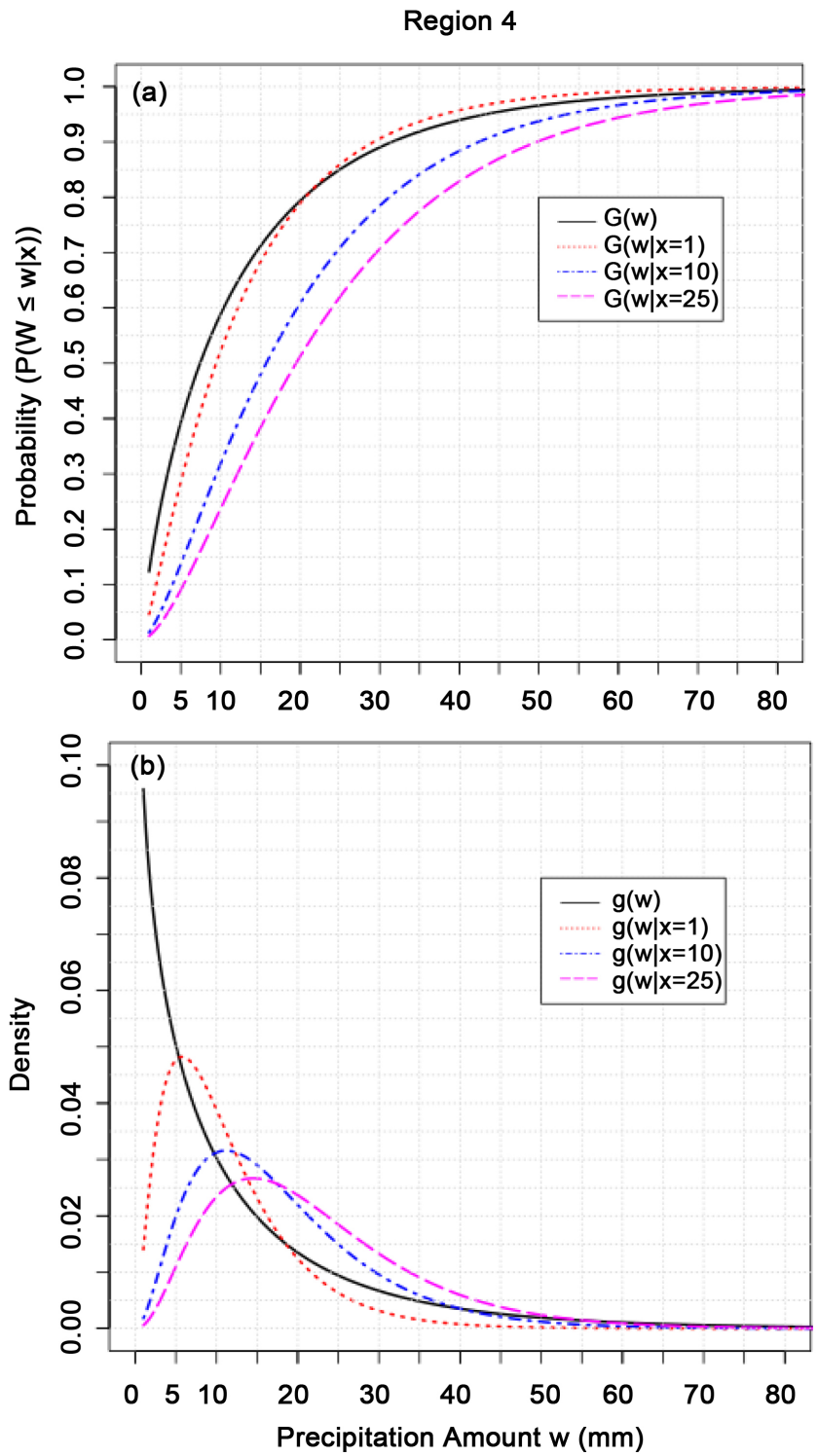

Figure 11. Examples of probabilistic forecasts of the precipitation amount $\mathrm{W}$, conditional on precipitation occurrence, $\mathrm{W}$ greater than 0 , and based on three different realizations $\mathrm{x}=1,10,25[\mathrm{~mm}]$ of predictor X for 24-h total precipitation amount output from the WRF model: (a) the prior (climatic) distribution function $G$ and three posterior distribution functions $G(w \mid x=1), G(w \mid x=10)$, $\mathrm{G}(\mathrm{w} \mid \mathrm{x}=25)$; (b) the prior (climatic) density function $\mathrm{g}$ and three posterior density functions $\mathrm{g}(\mathrm{w} \mid \mathrm{x}=1), \mathrm{g}(\mathrm{w} \mid \mathrm{x}=10), \mathrm{g}(\mathrm{w} \mid \mathrm{x}=25)$. 
posterior distributions functions. For simulated rainfall amount of $1 \mathrm{~mm}$, the probability of observing less than or equal to $20 \mathrm{~mm}$ rainfall is 0.8 ; that is $80 \%$ chance.

The probability of observing rainfall amount greater than $20 \mathrm{~mm}$ is $0.2 ; 20 \%$ chance.

For simulated rainfall amount of $10 \mathrm{~mm}$, the probability of observing rainfall $\leq 20 \mathrm{~mm}$ is 0.6 ; that is $60 \%$ chance. The probability to observe rainfall amount greater than $20 \mathrm{~mm}$ is 0.4 . The probability of observing rainfall amounts $\leq 20 \mathrm{~mm}$ knowing that the simulated rainfall amount is $25 \mathrm{~mm}$ is 0.5 and the probability to observe rainfall greater than $20 \mathrm{~mm}$ is 0.5 . Figure 11 (b) shows that the most likely values of rainfall knowing that the simulated quantities for 1 $\mathrm{mm}, 5 \mathrm{~mm}$ and $25 \mathrm{~mm}$ are respectively $5 \mathrm{~mm}, 12 \mathrm{~mm}$ and $15 \mathrm{~mm}$.

\subsubsection{Region 5}

Figure 12(a) represents the prior (climatic) distribution function $G$ and three posterior distributions functions. The probability of observing rainfall $\leq 10 \mathrm{~mm}$ for example knowing that the simulated quantity is $1 \mathrm{~mm}$ is $0.85 ; 85 \%$ chance. When the simulated quantities are $10 \mathrm{~mm}$ and $25 \mathrm{~mm}$, the probability of observing rainfall $\leq 10 \mathrm{~mm}$ are 0.75 and 0.72 respectively. The probability of observing rainfall amounts greater than $10 \mathrm{~mm}$ are 0.25 and 0.28 respectively. Figure 12(b) shows that the most likely values which can be observed are between 3 and $5 \mathrm{~mm}$ for simulated rainfall amounts greater than $1 \mathrm{~mm}$. It is noted that the most likely precipitations have low intensities. That means that heavy rainfalls are not recorded in the ocean during the JJAS season.

\subsubsection{Region 6}

For simulated rainfall amount of $1 \mathrm{~mm}$, the probability of observing rainfall $\leq 20$ $\mathrm{mm}$ is 0.8 and that to observe rainfall greater than $20 \mathrm{~mm}$ is 0.2 (see Figure 13(a)). When the simulated rainfall amounts are $10 \mathrm{~mm}$ and $25 \mathrm{~mm}$, the probability of observing rainfall $\leq 20 \mathrm{~mm}$ are respectively 0.7 and 0.65 and those to observe rainfall greater than $20 \mathrm{~mm}$ are respectively 0.3 and 0.35 . The most likely values of rainfall are $6 \mathrm{~mm}, 9 \mathrm{~mm}$ and $12 \mathrm{~mm}$ for simulated rainfall amounts of $1 \mathrm{~mm}, 10 \mathrm{~mm}$ and $25 \mathrm{~mm}$ respectively (see Figure 13(b)).

\section{Conclusion}

The Bayesian Processor of Output method was used to produce Probabilistic Quantitative Precipitation Forecast over Central and West Africa. It processes output from a NWP model and optimally fuses it with climatic data in order to quantify uncertainty about a predictand. Outputs from the Weather Research and Forecasting (WRF) model were used to develop and test the BPO technique. The model ran from June 01 to September 30 of 2010 and 2011. The BPO method was applied in each grid point and then in each climatic zones. Prior (climatic) distribution function was estimated from the Tropical Rainfall Measuring Mission (TRMM) data for the period 2002-2011. Many distribution functions have been tested for the fitting. Weibull distribution was found to be a 
Region 5
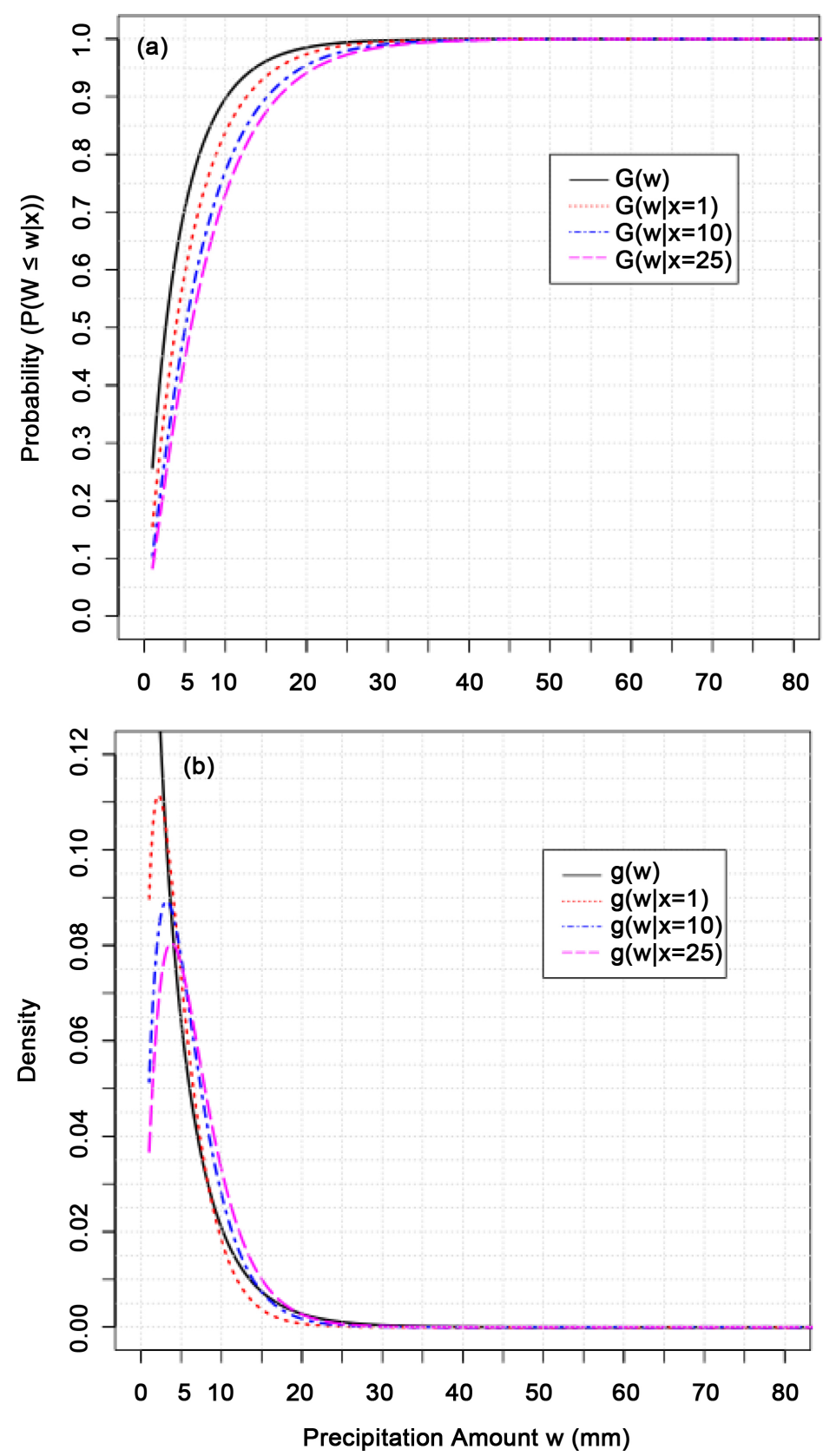

Figure 12. Examples of probabilistic forecasts of the precipitation amount $\mathrm{W}$, conditional on precipitation occurrence, $\mathrm{W}$ greater than 0 , and based on three different realizations $\mathrm{x}=1,10,25[\mathrm{~mm}]$ of predictor $\mathrm{X}$ for 24-h total precipitation amount output from the WRF model: (a) the prior (climatic) distribution function $\mathrm{G}$ and three posterior distribution functions $G(w \mid x=1), G(w \mid x=10), G(w \mid x=25)$; (b) the prior (climatic) density function $\mathrm{g}$ and three posterior density functions $\mathrm{g}(\mathrm{w} \mid \mathrm{x}=$ 1), $g(w \mid x=10), g(w \mid x=25)$.

suitable fitting function as shown by goodness of fit (gof) test in both cases. BPO method noticeably improves the distribution of precipitation as shown by the spatial correlation coefficients, reliability diagrams and relative operating cha- 
Region 6
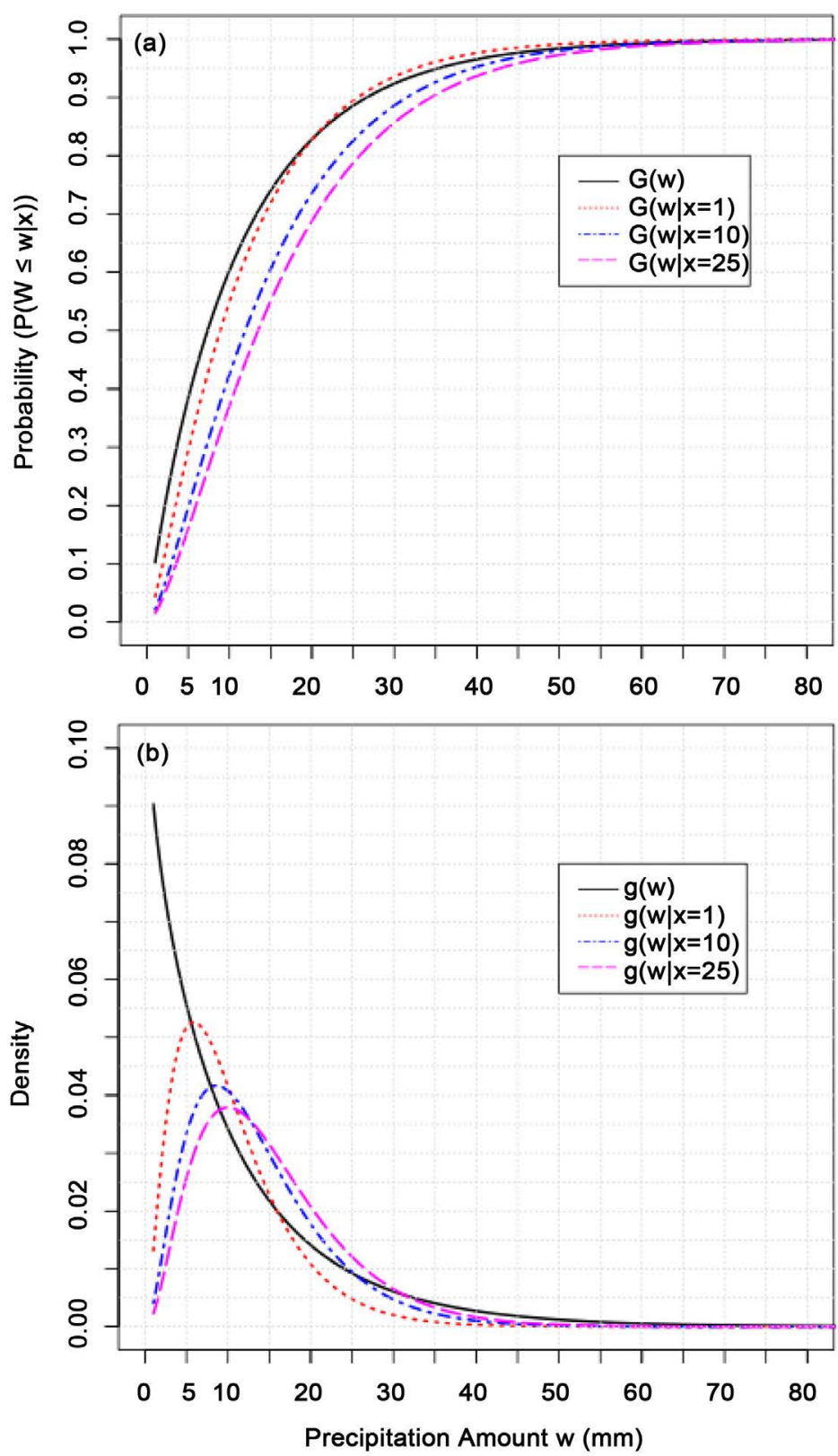

Figure 13. Examples of probabilistic forecasts of the precipitation amount $\mathrm{W}$, conditional on precipitation occurrence, $\mathrm{W}$ greater than 0 , and based on three diferent realizations $\mathrm{x}=1,10,25[\mathrm{~mm}]$ of predictor $\mathrm{X}$ for 24-h total precipitation amount output from the WRF model: (a) the prior (climatic) distribution function $\mathrm{G}$ and three posterior distribution functions $G(w \mid x=1), G(w \mid x=10), G(w \mid x=25)$; (b) the prior (climatic) density function $g$ and three posterior density functions $g(w \mid x=1)$, $\mathrm{g}(\mathrm{w} \mid \mathrm{x}=10), \mathrm{g}(\mathrm{w} \mid \mathrm{x}=25)$.

racteristic curves. It better detects certain observed maxima compared to the raw WRF outputs. Posterior distribution (forecasting) functions allow for a simulated rainfall amount, to deduce the probability that observed rainfall falls above a given threshold. The probability of observing rainfall above a given threshold 
increases with simulated rainfall amounts. The forecasting functions determined in the present paper can be used by forecasters as guidance for issuing probabilistic forecasts from a single deterministic forecast. In addition, this forecasting tool might assist forecasters throughout the season in a wide variety of weather events.

\section{Acknowledgements}

WRF simulations were done on a workstation provided by Dr Serge Janicot of LOCEAN (Paris), in the framework of the PICREVAT project, funded by the French government. WRF was provided by the University Corporation for Atmospheric Research website (for more information see http://www2.mmm.ucar.edu/wrf/users/download/get_source.html). GPCP data were obtained from the NOAA website http://www.esrl.noaa.gov. TRMM data were provided online by NASA at http://mirador.gsfc.nasa.gov.

\section{References}

[1] Janicot, S. (1992) Spatiotemporal Variability of West African Rainfall. Part II: Associated Surface and Airmass Characteristics. Journal of Climate, 5, 499-511. https://doi.org/10.1175/1520-0442(1992)005<0499:SVOWAR>2.0.CO;2

[2] Mkankam, K.F., Tsalefac, M. and Mbane, B.C. (1994) Variabilitépluviometrique sur le Territoire Camerounais: Essai de Régionalisation à Partir des Cumuls Mensuels et du Cycle Annuel. Publications de l'Association Internationale de Climatologie, 7, 439-446.

[3] Tchotchou, L.A.D. and Kamga, F.M. (2009) Sensitivity of the Simulated African Monsoon of Summers 1993 and 1999 to Convective Parameterization Schemes in RegCM3. Theoretical and Applied Climatology, 100, 207-220. https://doi.org/10.1007/s00704-009-0181-2

[4] Tanessong, R.S., Vondou, D.A., Igri, P.M.F. and Mkankam, K. (2012) Evaluation of Eta Weather Forecast Model over Central Africa. Atmospheric \& Climate Sciences, 2, 532-537. https://doi.org/10.4236/acs.2012.24048

[5] Trapero, L., Bech, J. and Lorente, J. (2012) Numerical Modelling of Heavy Precipitation Events over Eastern Pyrenees: Analysis of Orographic Effects. Atmospheric Research, 93, 408-418. https://doi.org/10.1016/j.atmosres.2009.01.021

[6] Richard, E., Buzzi, A. and Zangl, G. (2007) Quantitative Precipitation Forecasting in the Alps: The Advances Achieved by the Mesoscale Alpine Programme. Quarterly Journal of the Royal Meteorological Society, 133, 831-846. https://doi.org/10.1002/qj.65

[7] Stensrud, D.J. and Yussouf, N. (2007) Reliable Probabilistic Quantitative Precipitation Forecasts Froma Short-Range Ensemble Forecasting System. Weather and Forecasting, 22, 2-17. https://doi.org/10.1175/WAF968.1

[8] Ullah, K. (2012) A Diagnostic Study of Convective Environment Leading to Heavy Rainfall during the Summer Monsoon 2010 over Pakistan. Atmospheric Research, 120, 226-239.

[9] Hamill, T.M. and Colucci, S.J. (1997) Verification of Eta-Rsm Short-Range Ensemble Forecasts. Monthly Weather Review, 125, 1312-1327. https://doi.org/10.1175/1520-0493(1997)125<1312:VOERSR >2.0.CO;2

[10] Palmer, T.N. (2002) The Economic Value of Ensemble Forecasts as a Tool for Risk 
Assessment: From Days to Decades. Quarterly Journal of the Royal Meteorological Society, 128, 747-774. https://doi.org/10.1256/0035900021643593

[11] Gneiting, T. and Raftery, A.E. (2005) Weather Forecasting Using Ensemble Methods. Science, 310, 248-249. https://doi.org/10.1126/science.1115255

[12] Glahn, H.R. and Lowry, D.A. (1972) The Use of Model Output Statistics (MOS) in Objective Weather Forecasting. Meteorology, 11, 1203-1211. https://doi.org/10.1175/1520-0450(1972)011<1203:tuomos >2.0.co;2

[13] Bermowitz, R.J. (1975) An Application of Model Output Statistics to Forecasting Quantitative Precipitation. Monthly Weather Review, 103, 149-153. https://doi.org/10.1175/1520-0493(1975)103<0149:AAOMOS>2.0.CO;2

[14] Antolik, M.S. (2000) An Overview of the National Weather Service's Centralized Statistical Quantitative Precipitation Forecasts. Journal of Hydrology, 239, 306-337. https://doi.org/10.1016/S0022-1694(00)00361-9

[15] Bremnes, J.B. (2004) Probabilistic Forecasts of Precipitation in Terms of Quantiles Using NWP Model Output. Monthly Weather Review, 132, 338-347. https://doi.org/10.1175/1520-0493(2004)132<0338:PFOPIT>2.0.CO;2

[16] Friederichs, P. and Hense, A. (2007) Statistical Downscaling of Extreme Precipitation Events Using Censored Quantile Regression. Monthly Weather Review, 135, 2365-2378. https://doi.org/10.1175/MWR3403.1

[17] Applequist, S., Gahrs, G.E., Pfeffer, R.L. and Niu, X.F. (2002) Comparison of Methodologies for Probabilistic Quantitative Precipitation Forecasting. Weather and Forecasting, 17, 783-799. https://doi.org/10.1175/1520-0434(2002)017<0783:COMFPQ >2.0.CO;2

[18] Hamill, T.M., Whitaker, J.S. and Wei, X. (2004) Ensemble Reforecasting: Improving Medium-Range Forecast Skill Using Retrospective Forecasts. Monthly Weather Review, 132, 1434-1447. https://doi.org/10.1175/1520-0493(2004)132<1434:ERIMFS>2.0.CO;2

[19] Koizumi, K. (1999) An Objective Method to Modify Numerical Model Forecasts with Newly Given Weather Data Using an Artificial Neural Network. Weather and Forecasting, 14, 109-118. https://doi.org/10.1175/1520-0434(1999)014<0109:AOMTMN>2.0.CO;2

[20] Ramirez, M.C., Velho, H.F.C. and Ferreira, N.J. (2005) Artificial Neural Network Technique for Rainfall Forecasting Applied to the Sao Paulo Region. Journal of $\mathrm{Hy}$ drology, 301, 146-162. https://doi.org/10.1016/j.jhydrol.2004.06.028

[21] Gahrs, G.E., Applequist, S., Pfeffer, R.L. and Niu, X.F. (2003) Improved Results for Probabilistic Quantitative Precipitation Forecasting. Weather and Forecasting, 18, 879-890. https://doi.org/10.1175/1520-0434(2003)018<0879:IRFPQP >2.0.CO;2

[22] Yussouf, N. and Stensrud, D.J. (2006) Prediction of Near-Surface Variables at Independent Locations from a Bias-Corrected Ensemble Forecasting System. Monthly Weather Review, 134, 3415-3424. https://doi.org/10.1175/MWR3258.1

[23] Krzysztofowicz, R. and Maranzano, C.J. (2006) Bayesian Processor of Output for Probabilistic Quantitative Precipitation Forecasts. Systems Engineering and Department of Statistics, University of Virginia, Charlottesville.

[24] Wilks, D.S. (1990) Maximum Likelihood Estimation for the Gamma Distribution Using Data Containing Zeros. Journal of Climate, 3, 1495-1501. https://doi.org/10.1175/1520-0442(1990)003<1495:MLEFTG>2.0.CO;2

[25] Hamill, T.M. and Colucci, S.J. (1998) Evaluation of Eta-RSM Ensemble Probabilistic Precipitation Forecasts. Monthly Weather Review, 126, 711-724. https://doi.org/10.1175/1520-0493(1998)126<0711:EOEREP>2.0.CO;2 
[26] Wilson, L.J., Burrows, W.R. and Lanzinger, A. (1999) A Strategy for Verifying Weather Element Forecasts from an Ensemble Prediction System. Monthly Weather Review, 127, 956-970. https://doi.org/10.1175/1520-0493(1999)127<0956:ASFVOW>2.0.CO;2

[27] Sloughter, J.M., Raftery, A.E., Gneiting, T. and Fraley, C. (2007) Probabilistic Quantitative Precipitation Forecasting Using Bayesian Model Averaging. Monthly Weather Review, 135, 3209-3220. https://doi.org/10.1175/MWR3441.1

[28] Krzysztofowicz, R. (1983) Why Should a Forecaster and a Decision Maker Use Bayes Theorem. Water Resources Research, 19, 327-336. https://doi.org/10.1029/WR019i002p00327

[29] Skamarock, W.C., Klemp, J.B., Dudhia, J., Gill, D.O., Barker, D.M., Wang, W. and Powers, J.G. (2008) A Description of the Advanced Research WRF Version 3. National Center for Atmospheric Research, Denver.

[30] Hong, S.Y., Pan, H.L. and Lim, J.O.J. (2006) The WRF Single-Moment 6-Class Microphysics Scheme (WSM 6). Asia-Pacific Journal of Atmospheric Sciences, 42, 129-151.

[31] Mlawer, E.J., Taubman, S.J., Brown, P.D., Iacono, M.J. and Clough, S.A. (1997) Radiative Transfer for Inhomogeneous Atmosphere: RRTM, a Validated Correlated-K Model for the Long-Wave. Journal of Geophysical Research, 102, 16663-16682. https://doi.org/10.1029/97JD00237

[32] Tiedtke, M. (1989) A Comprehensive Mass Flux Scheme for Cumulus Parameterization in Large Scale Models. Mon. Monthly Weather Review, 117, 17791800. https://doi.org/10.1175/1520-0493(1989)117<1779:ACMFSF>2.0.CO;2

[33] Nordeng, T.E. (1994) Extended Versions of the Convective Parameterization Scheme at ECMWF and Their Impact on the Mean and Transient Activity of the Model in the Tropics. ECMWF Technical Memorandum, 206, 41.

[34] Huffman, G.J., Morrissey, M., Bolvin, D., Curtis, S., Joyce, R., McGavock, B., Susskind, J. and Adler, R.F. (2001) Global Precipitation at One Degree Daily Resolution from Multisatellite Observations. Journal of Hydrometeorology, 2, 3650. https://doi.org/10.1175/1525-7541(2001)002<0036:GPAODD>2.0.CO;2

[35] Gong, X. and Richman, M.B. (1995) On the Application of Cluster Analysis to Growing Season Precipitation Data in North America East of the Rockies. Journal of Climate, 8, 897-931. https://doi.org/10.1175/1520-0442(1995)008<0897:OTAOCA >2.0.CO;2

[36] Unal, Y., Kindap, T. and Karaca, M. (2003) Redefining the Climate Zones of Turkey Using Cluster Analysis. International Journal of Climatology, 23, 1045-1055. https://doi.org/10.1002/joc.910

[37] Rao, A.R. and Srinivas, V.V. (2006) Regionalization of Watersheds by Hybrid-Cluster Analysis. Journal of Hydrology, 318, 37-56. https://doi.org/10.1016/j.jhydrol.2005.06.004

[38] Yepdo, D.Z., Monkam, D. and Lenouo, A. (2009) Spatial Variability of Rainfall Regions in West Africa during the 20th Century. Atmospheric Science Letters, 10, 9-13. https://doi.org/10.1002/asl.202

[39] Dezfuli, A.K. (2011) Spatio-Temporal Variability of Seasonal Rainfall in Western Equatorial Africa. Theoretical and Applied Climatology, 104, 57-69. https://doi.org/10.1007/s00704-010-0321-8

[40] Nicholson, S.E., Some, B., McCollum, J., Nelkin, E., Klotter, D., Berte, Y., Diallo, B.M., Gaye, I., Kpabeba, G., Ndiaye, O., Noukpozounkou, J.N., Tanu, M.M., Thiam, A., Toure, A.A. and Traore, A.K. (2003) Validation of TRMM and Other Rainfall 
Estimates with a High-Density Gauge Dataset for West Africa. Part II: Validation of TRMM Rainfall Products. Journal of Applied Meteorology, 42, 1355-1368. https://doi.org/10.1175/1520-0450(2003)042<1355:VOTAOR >2.0.CO;2

[41] Huffman, G., Adler, R., Arkin, P., Chang, A., Ferraro, R., Gruber, A., Janowiak, J., Mc-Nab, A., Rudolf, B. and Schneider, U. (1997) The Global Precipitation Climatology Project (GPCP) Combined Precipitation Dataset. Bulletin of the American Meteorological Society, 78, 5-20. https://doi.org/10.1175/1520-0477(1997)078<0005:TGPCPG>2.0.CO;2

[42] Arkin, P.A. and Meisner, B.N. (1987) The Relationship between Large Scale Convective Rainfall and Cold Cloud over the Western Hemisphere during 1982-84. Monthly Weather Review, 115, 51-74. https://doi.org/10.1175/1520-0493(1987)115<0051:TRBLSC>2.0.CO;2

[43] Kelly, K.S. and Krzysztofowicz, R. (1995) A Bivariate Meta-Gaussian Density for Use in Hydrology. Stochastic Hydrology and Hydraulics, 11, 17-31. https://doi.org/10.1007/BF02428423

[44] Krzysztofowicz, R. and Herr, H.D. (2001) Hydrologic Uncertainty Processor for Probabilistic River Stage Forecasting: Precipitation-Dependent Model. Journal of Hydrology, 249, 46-68. https://doi.org/10.1016/S0022-1694(01)00412-7

[45] Krzysztofowicz, R. (2002) Bayesian System for Probabilistic River Stage Forecasting. Journal of Hydrology, 268, 16-40. https://doi.org/10.1016/S0022-1694(02)00106-3

[46] Tanessong, R.S., Vondou, D.A., Moudi-Igri, P., Kamsu-Tamo, P.H. and Mkankam-Kamga, F. (2013) Evaluation of Probabilistic Precipitation Forecast Determined from WRF Forecasted Amounts. Theoretical and Applied Climatology, 116, 649-659. https://doi.org/10.1007/s00704-013-0965-2

\section{Submit or recommend next manuscript to SCIRP and we will provide best service for you:}

Accepting pre-submission inquiries through Email, Facebook, LinkedIn, Twitter, etc. A wide selection of journals (inclusive of 9 subjects, more than 200 journals)

Providing 24-hour high-quality service

User-friendly online submission system

Fair and swift peer-review system

Efficient typesetting and proofreading procedure

Display of the result of downloads and visits, as well as the number of cited articles

Maximum dissemination of your research work

Submit your manuscript at: http://papersubmission.scirp.org/

Or contact acs@scirp.org 